Una trilogía: usos sociales, géneros y espacios de exposición. Las muestras de la Fotogalería del Teatro San Martín en 2018

Verónica Tell

Boletín de Arte (N.20), e025, septiembre 2020, ISSN 2314-2502

https://doi.org/10.24215/23142502e025

http://papelcosido.fba.unlp.edu.ar/ojs/index.php/boa

Facultad de Artes. Universidad Nacional de La Plata

La Plata. Buenos Aires. Argentina

\title{
UNA TRILOGIA: USOS SOCIALES, GÉNEROS Y ESPACIOS DE EXPOSICIÓN
}

\section{LAS MUESTRAS DE LA FOTOGALERÍA DEL TEATRO SAN MARTíN EN 2018}

\section{A TRILOGY: SOCIAL USES, GENRES AND EXHIBITION SPACES}

\section{SAMPLES OF THE PHOTOGALLERY OF THE SAN MARTÍN THEATER IN 2018}

\author{
Verónica Tell / veronicatell@gmail.com \\ Consejo Nacional de Investigaciones Científicas y Técnicas (CONICET). Centro de \\ Investigaciones en Arte y Patrimonio. Universidad Nacional de San Martin. Argentina
}

Recibido: $19 / 3 / 2020$

Aceptado: $12 / 7 / 2020$

\section{RESUMEN}

Tras cuatro años cerrada por reformas en el edificio que la alberga, la Fotogalería del Teatro San Martín reabrió en 2018 dirigida por tres curadores. Este texto es un análisis de las exposiciones realizadas ese año: la primera reunió obras de dos artistas que exploraron y cuestionaron formas convencionales de la fotografía; la segunda, de un solo autor, puso otra vez en primer plano una reflexión sobre la fotografía y los géneros; y la tercera abordó cuestiones relativas al espacio de exhibición y a la exposición de fotografías en particular. Propongo verlas como una trilogía sobre los usos sociales, los géneros y los espacios de exposición de fotografías, que se sirvió de la circularidad de referencias entre la Fotogalería, su historia y las obras para abordar el universo de sentidos del que las fotografías participan o pueden participar (espacios de exposición incluidos).

\section{PALABRAS CLAVE}

Fotografía; fotogalería; espacio institucional; exposiciones

\section{ABSTRACT}

After four years, the Fotogalería at Teatro San Martin reopened in 2018 under the direction of three curators. This text proposes an analysis of the three exhibitions that year. The first had works by two artists exploring conventional forms of photography; the second, a solo show, displayed, once again, a reflection on genres; and the third embraced questions on exhibition spaces, photographic ones in particular. My view is that they conform a trilogy about social uses, genres and exhibition spaces exploiting circularity between the Fotogalería, its history and the pictures, and that they allow an approach on the universes of meanings that photography have or may have (including the exhibition space).

\section{KEYWORDS}

Photography; fotogalería; institutional space; exhibitions 
La Fotogalería del Teatro Municipal General San Martín (TMGSM) —hoy Complejo Teatral Buenos Aires - comenzó a funcionar en 1985, bajo la dirección de la fotógrafa, editora y gestora Sara Facio. Fue una sala pionera en su dedicación exclusiva a la exhibición de fotografías y su actividad resultó crucial para la institucionalización del medio, es decir, para el desarrollo de espacios y de discursos dedicados de manera específica a la fotografía. Le siguió, al año siguiente, la creación del Foto Espacio del Centro Cultural Ciudad de Buenos Aires. Además, las exposiciones temporarias en el Museo Nacional de Bellas Artes, que culminaron una década más tarde con la creación de la colección fotográfica, marcaron la asimilación museística de la fotografía, algo secundado poco después, en 1999, por el Museo de Arte Moderno de la ciudad de Buenos Aires.

La primera exhibición de la Fotogalería fue «El retrato: maestros contemporáneos», bajo la premisa de que el retrato es la "disciplina madre" (Facio, 1985), y reunía obras de cuatro referentes indiscutibles de la fotografía en la Argentina (Grete Stern, Annemarie Heinrich, Horacio Coppola y Anatole Saderman). La octava muestra, que cerraba el año inaugural, estuvo consagrada al TMGSM mismo, para lo que se invitó a seis fotógrafos a recorrerlo y registrar tanto su arquitectura como sus espectáculos y su público. ${ }^{1}$

Durante cuatro años, y luego de más de diez bajo la dirección del fotógrafo y docente Juan Travnik, la sala estuvo cerrada por las reformas del teatro para no abrir hasta 2018. La dirección de la Fotogalería pasó, entonces, de ser unipersonal a convertirse en un triunvirato compuesto por Rosana Schoijett, Bruno Dubner y Ariel Authier —los tres, en diferentes proporciones y recorridos, artistas, curadores y gestores-. En un contexto en que la fotografía tiene una presencia cada vez más fuerte y legitimada en el terreno de las artes visuales, con más de una galería especializada, coleccionismo en alza y feria propia, sin dudas implicó un desafío recoger la tradición de la Fotogalería, dirigirse a su público concreto — marcado por la heterogeneidad de asistentes a espectáculos en el teatro, transeúntes de la avenida Corrientes y quienes acuden expresamente a ver las exhibiciones-, y ponerla en la agenda de la fotografía contemporánea.

Este texto presenta un análisis de las exposiciones realizadas por los curadores en su primer año de gestión. ${ }^{2}$ Quisiera señalar, en primer lugar, que el espacio de la Fotogalería no tuvo ninguna transformación estructural ni material, lo cual — dado que las paredes son de mármol y no pueden ser perforadas - impuso una limitación muy concreta en los montajes. Así, los curadores debieron ceñirse a un sistema de carriles y tanzas para colgar las obras, y trabajar con el espacio abierto, para lo que dispusieron una serie de planos inclinados y vitrinas.

\section{UNA TRILOGÍA}

La primera muestra que presentaron, "Máxima reserva. Lucrecia Plat y Carlos Ginzburg" (12 de junio - 5 de agosto), reunió obras de dos artistas que exploraron formas convencionales de la fotografía: Plat, desde la fotografía de sociales, y Ginzburg, anclando en la fotografía turística, para cuestionarla. Si bien hay una afinidad en ese punto, se trata de dos artistas con trayectorias y búsquedas muy distintas, y también los orígenes de ambas obras son bien diferentes.

Por un lado, en los años sesenta y setenta, una fotógrafa de prensa recorre inauguraciones, cócteles y boliches, y su flash construye máscaras, rostros que recuerdan a un Jorge de la Vega —dice Bruno Dubner (2018) en el texto de presentación-, pero también a un James Ensor - George Grosz. La sociedad engalanada para la fiesta nocturna, entre humos y burbujas, difícilmente pueda no resultar caricaturesca. Entre los vestidos largos que destellan ante las

1 Fueron Raquel Bigio, Guillermo Gruben, Ricardo Sanguinetti, Aldo Sessa, Juan Travnik y Julie Méndez Escurra. Además se expusieron fotos de Martín Siccardi, contratado por el Teatro para realizar retratos de actores. Otras muestras posteriores replicaron esta propuesta.

2 En 2019 Rosana Schoijett deja el comité curatorial y es reemplazada por Lara Marmor. 
luces artificiales de la noche y las caras de mujeres y de hombres sonrientes, copa en mano, podemos imaginar el ruido de la música y de las conversaciones cruzadas, y el aire viciado.

Por otro lado, a fines de los setenta, un fotógrafo y artista conceptual recorre países lejanos, y su cámara reproduce estereotipos. Uno, el del viajero en tiempos de turismo de masas $-\mathrm{y}$ tenemos aquí un cuestionamiento visual de aquello que Pierre Bourdieu (2003) abordó en Un arte medio- . Otro, el del exotismo: el cartel con el texto "E-SOT-ISME" delante de los distintos fondos - eso son, fondos - de regiones distantes enfatiza la intervención de la imagen sobre esos espacios: el aplanamiento, la indiferenciación. El fotógrafo, por su parte, mantiene en Bali, Creta o Marruecos la misma expresión en su rostro, y la ropa y el bolso colgado de lado se suman a la monotonía del tipo de toma en la que posa delante de los sitios que ha conquistado como turista. Sujeta a los usos convencionales, ¿puede la fotografía producir algo que no lo sea, una imagen que no ratifique las construcciones iconográficas (e imaginarias) previas?

Alguna foto de cada uno se aleja del grueso del conjunto. En el caso de Plat se trata de la fotografía de una joven dentro de una bañadera hablando por teléfono —la imagen elegida para la difusión de la muestra-. La mirada incisiva de Plat no se arroja, como en las otras, al estridente entorno de una boîte, sino que el punto de cámara y la expresión de la mujer, en un espacio privado y con el maquillaje corrido, congelan una escena cuya continuación no podemos predecir. Como si se tratara del fotograma de una película de suspenso o del cinema vérité...

En cuanto a Ginzburg, dos imágenes cortan con los destinos exóticos para convocarnos a un pequeño viaje en el tiempo al interior del edificio que alberga la Fotogalería. Las fotos registran la obra del artista en la muestra "Arte de sistemas" del Centro de Arte y Comunicación (CAyC), de 1971, en el Museo de Arte Moderno, que funcionaba entonces en el edificio del CTGSM. Un cartel sobre la valla del lote baldío junto al edificio del Teatro invitaba al transeúnte a ver un "trabajo artístico escondido", para lo cual debía seguir ciertos pasos anunciados a medida que avanzaba que, resumidos, implicaban ingresar al edificio, tomar los ascensores hasta el noveno piso y asomarse por la ventana para encontrar escrito con cal, en el lote baldío y justo al otro lado de la valla donde comenzó su itinerario, la palabra "tierra». El efecto de circularidad o de reenvío que esperaba suscitar la obra original —entre la calle y el museo, el transeúnte y el espectador, la palabra y la experiencia- se replica en la exposición de 2018, con estos dos registros fotográficos (del cartel y la vista desde el noveno piso) colgados al lado de los ascensores, que hacen que el observador contemporáneo entre en un loop con su par histórico mientras reordena las coordenadas de espacio y tiempo.

Como se verá luego, el registro de la obra de Ginzburg conecta a esta primera exposición con la tercera del año. Pero por lo pronto, consideremos que sobre esta muestra —una lectura crítica sobre los lugares y discursos de cierta fotografía - recayó el peso de inaugurar la nueva etapa de un espacio ciertamente marcado por su historia y por curadores previos, resultando sin dudas una apuesta interesante.

La segunda exposición, "El Segundo sin sombra. Gustavo Di Mario» (21 de agosto - 21 de octubre) focalizó en este solo autor y en su ensayo sobre un tema bien específico: los gauchos, serie en la que trabaja desde 2004. Fotógrafo de moda además, Di Mario asiste a las domas y jineteadas para registrar no las intrépidas acciones de la masculinidad gaucha, sino las poses, las esperas y las preparaciones tras bambalinas. En los márgenes de la tradición iconográfica y de la persistencia de un modo de vida, los caballos conviven con las camionetas, los cercos con las estaciones de servicio y accedemos a la "deconstrucción del arquetipo folclórico" (Schoijett, 2018). El folclorismo y aquella identidad nacional construida en torno al gaucho hace más de un siglo - y que Di Mario rehúye en sus retratos hechos durante (y no en) las jineteadas y fiestas - representa para los curadores la ocasión para poner otra vez en primer plano una reflexión sobre la fotografía y los géneros. Las fotografías, en su gran mayoría en 
blanco y negro, reponen formas clásicas de representación: encuadres centrales y retratos con miradas a cámara. Pero en una de las paredes, un tríptico de caballos y jinetes propone una configuración que quiebra la unidad de tiempo y espacio: bajo este rasgo linda con lo cinematográfico y expande el cuestionamiento también hacia el medio fotográfico mismo.

La tercera exposición, "El espacio rasgado» (14 de noviembre - 10 de marzo) abordó aspectos relativos al espacio de exhibición, en una propuesta visualmente despojada. La muestra estaba compuesta por pocas obras distribuidas de manera irregular, concentradas sobre todo en el sector de ingreso de la sala desde el Teatro. Esto supone una clara distancia respecto de las formas exhibitivas más tradicionales que sostuvo la Fotogalería bajo los curadores y los programadores anteriores y, aun, en las dos exposiciones previas del año 2018.

Tres fotografías o series de fotografías históricas conviven con tres piezas especialmente producidas para la exhibición: instalaciones de Miguel Mitlag y de Ariel Mora y un video de Joaquín Ares. La pieza clave de la muestra es un objeto casi fundacional: se trata de una fotografía del espacio tomada por Sara Facio al poco tiempo de haberse inaugurado como Fotogalería. En el primer plano a la izquierda se ve, casi como si se tratara de un custodio o patrono de la sala y de lo allí expuesto, la maciza obra de Sesostris Vitullo (ubicada allí hasta su traslado al jardín del Museo Sívori). Cerca de ella se proyecta el video de Ares centrado en esa escultura y en sus emplazamientos. De este modo, el video funciona como vehículo entre el pasado —el de la fotografía de Facio—y el presente —o, más bien, un pasado más reciente- . También, por su bidimensionalidad, por el blanco y negro, y por el dispositivo de antecedentes fílmicos, el video establece un lazo entre las obras fotográficas y las no fotográficas, a la vez que la proyección, realizada sobre el muro granítico, alude a la materialidad de la pieza escultórica de Vitullo.

Para esta propuesta curatorial — que apunta a la historia de la sala y, de modo más amplio, a la exposición de fotografías, según señala Authier (2018) en el texto de pared-los curadores bucearon en archivos pertenecientes al San Martín (a su Centro de Documentación de Teatro y Danza Ana Itelman) para ubicar otras imágenes fundacionales. Así recuperaron fotografías que registran la construcción de ese sector del edificio municipal. En un efecto circular, cuelgan de las paredes los registros fotográficos de las obras que les dieron origen y, en ese movimiento, se conforman como piezas de exhibición unas imágenes de archivo — con sus soportes de papel e inscripciones- que hubiéramos imaginado como confinadas al mismo.

Si en esas tres piezas se juega algo relativo al espacio específico de la Fotogalería, la serie de fotografías de Carlos Militello que registran "Acción de encierro" (1968), de Graciela Carnevale - acción durante la cual los visitantes a una galería de Rosario eran encerrados de modo sorpresivo, y debían resignarse o actuar (rompiendo el vidrio) para liberarse-, evoca, de modo más general, la situación del espectador dentro de una sala de exhibición y su rol en la obra pudiendo ser él, de modo voluntario o no, quien la active, la ejecute o, incluso, la encarne.

Y ahí estamos nosotros hoy, en el interior de una sala emblemática que configuró localmente un modo para la exhibición de fotografías y basculamos entre lo que conocemos y esperamos, y esta propuesta con muy pocas fotografías colgadas (las de Facio y las del Centro de Documentación), algunas más en dos vitrinas (de Carnevale), un video y dos instalaciones. Estas aluden a un presente o un futuro de la fotografía y/o de su exhibición. Mora superpone vidrios transparentes con cinta adhesiva en sus lados. Imagen ausente, queda la pura materia frágil e invisible que suele protegerla. Un vidrio que tanto puede esperar la foto que vendrá como aludir a la vidriera rota en la performance de Carnevale (¿es acaso una invitación a la acción?). En la transparencia de los vidrios reverbera aquella que tanto tiempo se atribuyó a la fotografía — presunta imagen fiel, representación mimética—. Y a la vez, estos vidrios reflejan la sala a nuestras espaldas y nos reflejan a nosotros mismos. 
Por último, nos topamos con un cuerpo tridimensional e irregular de color rojo, con una foto colgada en su cara frontal (Escenario, de Mitlag, 2018). En realidad es lo primero que vemos al ingresar a la Fotogalería desde el Teatro y nos obtura la visión de la sala en su sentido longitudinal. Si la fotografía, como se dice comúnmente, es una ventana abierta al mundo, el universo de las exposiciones puede ser un velo a descorrer, una invitación. Al menos es lo que podríamos pensar al detenemos en la fotografía que pende de la estructura de Escenario, en la toalla y la cortina de ducha allí representadas: en ese objeto banal, cotidiano y de un siempre escaso atractivo estético, quizás es dable hallar una alusión —irónica-a los telones de los escenarios que en el mismo edificio abren paso a las representaciones teatrales. Una pregunta podría dirigirse entonces a la naturaleza y a la funcionalidad de esos espacios (sala de exhibición y sala teatral, ambas al interior de un inmenso complejo abocado principalmente a las artes escénicas), y a la relación de cada uno de ellos con la ficción.

Así, junto con las referencias a la historia de esta sala emblemática, "El espacio rasgado" sugiere una interrogación más amplia. A través de la coerción - Acción de encierro, de Carnevale, 1968- y de la invitación —Escenario, de Mitlag, 2018-, se establece una suerte de contrapunto que deja al descubierto que el espacio de exhibición no consiste en un continente inexpresivo, sino que nos compele a actuar, a decidir y a reflexionar. Ahora bien, dadas la trayectoria del lugar y la heterogeneidad de sus visitantes, quedaría por ver si la Fotogalería resulta el marco pertinente para esta sugerencia, o si esta última exposición no es en exceso hermética, si no hospeda grandes probabilidades de dejar afuera del juego de referencias y de sentidos al grueso del público real que la frecuenta. La obra de Mitlag, además, "que pone en escena una imagen en el espacio, autosuficiente, brutal y enigmática como una esfinge" (Authier, 2018), ${ }^{3}$ tiene una particularidad respecto de las otras dos piezas comisionadas. Los vidrios de Mora - al fin y al cabo materia frecuente en una galería fotográfica- y el video de Ares tienen por objeto o tema una proximidad con la sala y su historia (pensemos en la predominancia de lo bidimensional, el formato pequeño y mediano, y la fotografía enmarcada que fueron las formas predominantes de la fotografía allí exhibida). Esta escultura fotográfica, en cambio, resulta una forma extraña, extranjera.

\section{CONCLUSIÓN}

La comisión e inclusión de "Escenario» (2018), de Mitlag, marca sin dudas una intención rupturista por parte de los curadores respecto de los modos de sus antecesores e incluso de sus propias muestras previas. Pero si hallábamos una potencia en la intervención crítica sobre los usos sociales, los géneros y los espacios de exposición de fotografías que estas tres exhibiciones venían hilvanando, ésta radicaba principalmente, a mi juicio, en hacerse desde el interior del medio fotográfico, al emplear los mismos elementos — contravenidos, travestidos y desencajados - para abordar el universo de sentidos del que las fotografías participan o pueden participar, y producir un discurso crítico sobre la imagen y sus significados y contextos (espacios de exposición incluidos). En la medida en que la heterogeneidad deja expuesta la condición archivística, comunicacional e industrial de la fotografía —cuestionando su autonomía y autosuficiencia artística-, indagar de modo paralelo sobre la fotografía, y sobre y en un espacio de exposición público y masivo como es la Fotogalería, puede ser un gesto significativo en una escena global en que el mercado de arte devora vintages (o puede ser precisamente lo contrario).

\section{REFERENCIAS}

Authier, A. (2018). El espacio rasgado [Texto de sala de la exposición]. Ciudad Autónoma de Buenos Aires, Argentina: Fotogalería del Teatro San Martín.

Bourdieu, P. [1965] (2003). Un arte medio: ensayo sobre los usos sociales de la fotografía. Barcelona, España: Gustavo Gili.

3 El destacado es mío. 
Dubner, B. (2018). Máxima reserva. Lucrecia Plat y Carlos Ginzburg [Texto de sala de la exposición]. Ciudad Autónoma de Buenos Aires, Argentina: Fotogalería del Teatro San Martín.

Facio, S. (1985). El retrato. Maestros contemporáneos [Folleto desplegable]. En exposición Maestros contemporáneos: Argentina [Exposición]. Ciudad Autónoma de Buenos Aires, Argentina: Foto Galería Permanente.

Schoijett, R. (2018). El Segundo sin sombra. Gustavo Di Mario [Texto de sala de la exposición]. Ciudad Autónoma de Buenos Aires, Argentina: Fotogalería del Teatro San Martín. 